\title{
Drug Addictions and Sexual Violence in Childhood and Adolescence: Analyzing Life Stories
}

\author{
Andréa Marques Leão Doescher, Andreza Marques de Castro Leão and Paulo Rennes Marçal Ribeiro \\ Department of Educational Psychology, UNESP—São Paulo State University, Araraquara 14805-292, São Paulo, Brazil
}

Received: October 14, 2013 / Accepted: January 16, 2014 / Published: January 31, 2014.

\begin{abstract}
The sexual abuse suffered in childhood and adolescence, in addition to damage to physical and psychological health of the victim, is considered as an important risk factor for alcohol and drugs addiction, development of psychopathology and psychosocial damage in adulthood. In addition to the pain and humiliation that are submitted by the abuse, children and adolescents also experience shame and guilt which require them to adopt coping strategies to endure those feelings. The use of psychoactive substances is a recognized way of dealing with the pains of living. This work, which is of narrative style, analyses and discusses, through five case reports, chemical dependency as a result of sexual abuse suffered in childhood and/or adolescence. The eight subjects in this study are male and have suffered sexual violence in this age period of life. Their ages range from 23 years to 39 years, and all are admitted to a therapeutic community in a city in the interior of Sao Paulo state, in Brazil, for treatment of chemical dependency, being met by the Department of Psychology. The reasons for the choice of the participants for treatment modality for patients are: difficult to stop using drugs, even unwilling to take it, they have easy access to it; the feeling of losing control over their lives; by successive losses as a result of drug use, and for fear that their lives had a tragic ending. With the exception of two participants, the others do not classify that as a child suffered sexual violence. However, all attribute that facilitated their entry into the world of drugs. Seven participants experienced such violence in childhood (between 7 years and 9 years) and adolescence (age 14). The attackers were people closed to the victims-in the case of two victims, their families, with the exception of one participant who was raped by a stranger. Six participants declared themselves as homosexual. Another participant does not claim to be homosexual, but presents difficulties in terms of sexuality. Two participants are HIV positive. The start of psychoactive substances use occurred during adolescence (12 years to 17 years). The participants see drugs as an anesthetic to the pain of the soul, a way to get pleasure, but they get charged expensively, as it increases the feeling of emptiness, guilt, helplessness, worthlessness and hopelessness. Although participants have sought help to deal with addiction, it is noted that throughout the life course the issue of sexual violence was not treated. It was noted that the patients have a double stigma in society: the issue of drugs addiction and the orientation of sexual desire, because the majority of participants are homosexual. The results reinforce the need for effective action geared to accommodate the victims of sexual violence and effective preventive measures to prevent children and adolescents from being abused.
\end{abstract}

Key words: Sexual violence, childhood and adolescence, male gender, chemical dependency, sexuality.

\section{Introduction}

Sexual violence is a complex issue that has raised room to problematize. Since the beginning of the 1990s, sexual violence against children and adolescents is in evidence, and this is because society is more sensitive to this matter [1]. An interesting aspect that the researcher pointed is that growth of intimacy, the appreciation of the intimate life and

Corresponding author: Paulo Rennes Marçal Ribeiro, Ph.D., professor, research fields: psychology, sex education and mental health. E-mail: paulorennes@fclar.unesp.br. sexuality nowadays focus the look on trauma, and in the psychological consequences of sexual violence, because sex crimes generate psychic death, and it breaks the identity of the victim.

There are various forms of sexual violence practices against children and adolescents, among them: prostitution, trafficking for sexual purposes, sexual harassment, exhibitionism, voyeurism, sexual abuse, pornography, among others. Note that the subject is in itself large and complex.

Thinking about sexual abuse, you can set it as the 
participation of a child or an adolescent under 14 in sexual activity that is not able to understand, inappropriate to their age and their psychosexual development [2]. In fact, all forms of sexual activities in which children and adolescents do not have mature conditions, cognitive and psychological to endure, and that somehow violates the laws and social rules and morals is considered abuse.

In the sexual abuse, the victim is physically forced or emotionally coerced to participate in an intimacy without necessarily having the emotion or cognitive capacity to consent or judge what is happening [3]. Moreover, children are vulnerable to sexual assault, because they rely on adults who are their benchmark of what is and is not socially acceptable [4].

Summarizing, can be affirmed that sexual abuse is the touch of the entire body, or parts of it, of children or teens to satisfy sexual desire of older people (about 5 years minimum age difference), in which use power to coerce them. It is indeed a crime that occurs in different classes, in different cultures and ethnicities. There is no ethnicity, religious belief, political or social stratum immune to its occurrence.

According to the Brazilian Penal Code, the age difference between the offender and the victim must be greater than five years, so that the contact is considered as sexual abuse [2].

Sexual abuse is not linked primarily to physical assault; it may also be considered the caresses, kisses and seductive words. It can also be the sensory stimulation (pornography, obscene language sexy), the touching of the child's sexual organs, trial and/or vaginal penetration, oral, anal and masturbation, as well as induction of embarrassing situations for group sex [5].

Sexual abuse includes a variety of acts from caressing, touching genitals, breasts or anus, voyeurism, exhibitionism, to the sexual act itself, with or without penetration.

Sexual abuse may not involve physical contact, and it can occur through open conversations and proposals in order to instigate children's sexual interest, or by observing their intimate body parts, or even consist of showing the genitals to them [4]. In addition, children may be forced to watch pornographic movies and pictures, physical contact can happen, caress, and even vaginal, oral and/or anal sex. Finally, the previous mentioned researcher, indicates that sexual abuse in a child or adolescent is used as sexual gratification to the rapist.

Sexual abuse is classified as in home, and out home and institutional [1]. Out home abuse occurs outside the family, usually being practiced by acquaintances of the child and adolescent, who may be a neighbor, a professional who assists the victim, among others. It is usually a trusted person who is very close to the family. There is also abuse in home, which occurs at the home setting, involving people close to the victim or caregivers, as: fathers, stepfathers, stepmothers, uncles, grandparents, cousins, among others. Within this classification, there is still institutional violence, when it occurs in institutions that should take care of children, for example, daycares, schools, and others. The in home sexual abuse is the one that generates most threatening and psycho-emotional implications [1].

The sexual abuse in home is any activity of sexual nature in which the abuser has blood connection with the victim [6]. According to those authors, this type of abuse involves impacts psycho-emotional adjustment difficulties such as emotional, feelings of guilt, depression, isolation, relationship problems and communication, and so forth.

Regarding to the sex gender of the victimized, it is emphasized that the sexual abuse of children and adolescent males are underreported, which promotes the belief in society that the problem is not uncommon [7]. Although many authors assert that most abuse victims are female is important to note that this is still an issue that needs to be discussed [1]. Authors also expose that both girls and boys are vulnerable to this type of child maltreatment [8]. In the case of males, Schraufnagel et al. [9] mentioned that the childhood 
sexual abuse of boys is not uncommon, with around $14 \%$ of men were sexually abused in childhood, although this percentage can be significantly higher due to the silence. In fact, the abuse can happen in homosexual or heterosexual scenery.

Regarding to the implications of sexual violence suffered, these reverberates on health, physical, mental and social health of the victim, extending far beyond the occurrence of abuse [7].

Moreover, the child or adolescent can make use of PS (psychoactive substances) as a way of dealing with the occurrence of sexual abuse. According to Boruchovitch [10], psychological problems have interrelationship with drug use, and people take PS as a way to escape and be relieved from their problems, the same occurring to teenagers.

The use of these substances in adolescence can be classified into five motivational patterns: experimental, for curiosity and adventure, recreational, social, seeking pleasurable experiences to share with friends, use circumstantial-situational, in which the adolescent is motivated by the need of achieving a mental state in some circumstance; intensified use, it involves the use of long-term drug as a way to escape problems, and finally, the compulsive use, where drugs are used with high intensity and frequency, and such people, life without such substances is empty and sad [10].

Thinking about vulnerable situations in which children and adolescents victims of sexual abuse are exposed, it is necessary to find ways to cope with this problem, because they can make use of these substances as an attempt to deal with difficult situations such as: pain, suffering, shame, guilt, etc.; and those feelings are very difficult to cope. It is needed to think about primary prevention, before the initiation to the use of PS.

There are three ways to prevent sexual violence, which are: primarily: consists in the education of the child so that they know their rights about their body and that no one should touch them if them do not desire; secondarily: early identification preventing acts of abuse recur; thirdly: the prevention center for rape victims in crisis, with full monitoring of the victim and the aggressor [3].

However, these preventive measures are difficult to put into practice, since many abuse victims decide to be in silence because of the fear of the results of confession. Moreover, when they do reveal, in general, they are not given any support. And it is precisely in these situations that they need to be more accepted. If not, they may make use of PS and at some point in their lives, look for treatment for Chemical Dependency.

To talk about prevention is needed discuss sexuality, and not always as this subject is discussed on the agenda which is the issue of sexual violence [1]. Indeed, beyond the violence a little issue addressed is how the mental and physical effects that drugs cause to users. And it is precisely because they are not commonly treated subjects the school is called to contribute to the discussion of these issues.

Thus, it is evident the importance of school geared to discussing this matter with informative and preventive approach preventive actions. Although sexual violence is an embarrassing subject, it needs to be questioned in the different social levels, between those in school. In fact, the author explains that students should be know how to identify any suspected abuse situation, and whom to report to ask for help, as well as sensitize them so that they realize the harm that drugs bring [4].

Based on this, the study aims to analyze and discuss the life history of drug addicts who have suffered sexual abuse in childhood or adolescence and who are currently in drug treatment in voluntary hospitalization.

\section{Methodology}

The study is a qualitative one. Qualitative research works with values, beliefs, customs, ways of acting, representations, opinions and trys to deepen the complexity of facts and processes specific and reserved to individuals and groups [11]. A qualitative approach was employed for understanding phenomena 
marked by a high degree of internal complexity.

Among the qualitative research, opting for the life story is aim to capture what happens in the intersection of the individual with their social environment [11]. The cited author elucidates that history of life can be an instrument for analysis and interpretation, considering that it incorporates subjective experiences combined with social contexts, thus providing consistent basis for understanding the individual component of the historical phenomena. It complements that the story of life is commonly taken from one or more designated long interviews in which the interaction between researcher and researched occurs continuously.

In summary, the history of life is a methodology that is concerned with the relationship between researcher and subject, thus contributing to a committed, friendly and participatory listening, remembering the story of the individuals which are both the history of the team, that is, of the society of which it is part.

\subsection{Participants}

Eight men, who experienced sexual violence in childhood or adolescence, participated in the research. Their ages range from 23 years to 39 years, and all were admitted to a therapeutic community in the interior of Sao Paulo, Brazil, for treatment of chemical dependency, being met by the service of Psychology. The reasons for the choice of participants by treatment modality for inpatients are: difficult to stop using psychoactive substance even unwilling, easy access to its attainment, the feeling that they lost control over their lives, by successive losses due to psychoactive substance use, and the fear that their lives would have a tragic ending.

\subsection{Data Collection Instrument}

The authors utilized semi-structured interview and a diary, in which the interviews were recorded.

The semi-structured interview was chosen because it opens the possibility for the interviewer to follow a script and one can insert the same during the interview. In this context, the interview, which was prepared with the assistance of experts from the fields of Psychology, Chemical Dependency and Sexual Violence, encompassed the following items: sociodemographic data, using SPA (substances already used, start using, use evolution and treatments subjected), sexual behavior (practical use of condoms in situations that did not use the SPA and when use was made of this, sexual intercourse after using SPA or concomitantly with this, beliefs about sex and SPA), sexual abuse (age the occurrence abuser (intrafamilial, extrafamilial, institutional) circumstances in which it happened, revealed that the victim and who, treatment received, among others).

Having a field diary is a rich instrument, because you can write down the relevant facts and circumstances, which can be redeemed after the occurrence thereof. In this paper, verbal and nonverbal behaviors (facial expressions, psychomotor agitation, changes in voice, among others) of the participants during the interviews were recorded.

\subsection{Procedure for Data Collection}

Participants were contacted in the therapeutic community through the Psychology Department of the institution. So after the presentation of the work and its goals for the psychologist in charge, and the consent of the professional engineer and that the therapeutic community, participants were contacted and invited to participate in the study, and on this occasion they were informed of the objectives. Varying from two to three meetings a minimum duration of 50 minutes each, which occur within the affected community - then with the approval of them, the interviews were scheduled. It is worth noting that it was explained to them that these data would be used for the preparation and disclosure of the present study.

\subsection{Procedure for Data Analysis}

The interviews and field diary were analyzed 
qualitatively, and their contents grouped into categories for analysis. The process for the categories elaboration was based on the interpretation of the content present in the speeches of the participants.

Bardin [12] stated that categorization is a sort of organization operation of the constituent elements of a set, doing differentiation and then by regrouping analogically, aiming to simplify the representation of the raw data.

In the content analysis, it has chosen the thematic analysis, because it is more appropriate, since it focuses on the identification of themes as registration units, showing testimonials, comportment patterns, values, beliefs, provisions that are found in the data collected.

\section{Results}

With the exception of two participants, the others did not affirmed that suffered from sexual violence in childhood or adolescence and, one of them stated that it was "naughty since childhood" (sic). However, all attribute that this favored their entrance into the world of drugs.

The onset of substance use occurred in adolescence (between 12 years old and 17 years old), through alcohol; currently all of the respondents are crack users, besides alcohol and tobacco.

Seven participants cited that suffered violence in childhood (between 7 years old and 9 years old), and adolescence (age 14). The attackers were people near from the victims - in the case of two victims, their families, except for one participant who was raped in their adolescence by a stranger while returning from school to home.

Participants did not tell their abuse to adults when it occurred, due to: fear, shame, guilt, insecurity and because they think their story would not be treated as true. None of the participants even three of them who have been hospitalized for treatment of chemical dependency on other occasions were attended by professionals to help them. One of the participants said that he had never disclosed the abuse to anyone, and that even being in the 9th admission to the therapeutic clinic for drug users, this was the first time that a professional approached the subject.

Two participants are HIV positive to HIV and both believe they have contracted this disease through unsafe sex.

Only one participant did not declare himself as homosexual, but has conflicts about sexuality and expressive shyness, and even having 23 years old, he never dated and had consented sex.

Participants who declare themselves as homosexual reveal significant mental suffering due to their sexual orientation, because they feel "disobeying a sacred law"-a heterosexual relationship, for "being in sin" for "not being normal", by difficulties faced for being gay (believe life is harder for them), by family conflicts due to their condition and doubt that God loves them. In addition, all participants stated that if they could choose, they would not be gay but heterosexual.

Regarding the use of PS, the participants see drugs as an anesthetic pains to the soul, a way to get pleasures that afterwards will charge them expensively, because it enhances the feeling of emptiness, guilt, helplessness, worthlessness and hopelessness.

Their Dreams? "Being normal", having a "normal life” and be happy!

\section{Discussion}

Sexual violence is an unfortunate reality in today's context. However, it is necessary that the discussions of theories be able to be effectively applied, so that the alarming statistics of victims of abuse can be mitigated. Therefore, it is necessary to articulate effective strategies to stop this matter.

The results of this study highlight the need for effective actions aimed to accommodate the victims of sexual violence, and effective preventive measures to prevent children and adolescents from being abused.

Incidentally, it is revealed the need for a thorough evaluation of early interventions when one considers 
the situation of abuse, because it is necessary to help the teens not to use alcohol or other PS or have risky sexual behavior. In addition, the Chemical Dependency has been seen as a public health problem, since the disastrous consequences have led to the Brazilian and people from other countries.

A vast sex education can be a fruitful possibility. With it, one can work different subjects, such as sexual violence, and the orientation of sexual desire. Urge to break with the stigmas and labels because it can not be more accepted that children and adolescents are physically and emotionally abused, being pushed to make use of PS as a solution to their ills. Moreover, they are targets of bullying because of their sexual desire orientation.

Moreover, considering that sexual abuse in childhood and adolescence is a risk factor to the beginning of the use of PS in adolescence and adulthood, it is important that professionals, especially those who care for addicts, investigate this possibility, so that these people are obviously treated and accepted. Therefore, it is necessary to examine in detail the possibility of using these substances as a way of coping or escape the sexual abuse situation, especially in cases where adult patients relapsed many times.

In summary, the results highlight the importance of effective actions aimed to help the victims of sexual violence, and effective preventive measures to prevent children and adolescents from being abused.

Furthermore, the use of PS in adolescence can be enhanced due to several factors, such as chaotic home environment with parents who are PS users, with the presence of violence (physical, psychological or sexual) domestic, lack of dialogue and emotional involvement between parents and children, lack of clear rules of conduct and lack of parental authority; dissatisfaction and failure to carry on their activities; inappropriate shyness; perception of approval to the use of PS by family, school, friends, or community; insecurity; sensation of not belonging to anyone or anything, the need for something concrete that allows them to escape their problems and conflicts, even temporarily [13].

According to the authors, "the young who is sad, discouraged or even anxious, will look for things or activities that help them to feel better. The effects of drugs work temporally as a 'remedy' for their problems: these teens will use drugs as an attempt to get self-cured" [13].

Schraufnagel et al. [9] point to the risk of alcohol use among survivors of sexual abuse in childhood and adolescence. It is reiterated that the use of PS, in general, is a way to escape from the problem of being abused.

The issue of sexual abuse when not diagnosed and treated on time can be a big gap for the use of PS by the adolescent, since it is able to "numb" the pain of the soul, is a problem that requires coping strategies.

Studies have shown that early use of alcohol and drugs happens mostly in adolescence, and alcohol is the most commonly used drug by adolescents [13]. It is noteworthy that the onset of alcohol and drugs by adolescents does not happen by chance, but reflects the result of a "complex dialogue between risk factors and protective factors, in which the adolescent is immersed" [13].

The report of the first national survey on the patterns of alcohol consumption in the Brazilian population revealed that the onset for regular alcohol use was 14 years old for boys and 17 years old for girls. These data show that the use of PS is a serious thing, and is considered a public health problem that starts usually in adolescence.

The continued use of PS causes changes in the structure and functioning of the brain, resulting in the development of Chemical Dependency, which is defined as a progressive, chronic and recurrent, multifactorial, that goes beyond the phenomena caused or triggered by drugs, covering also the individual susceptibility and social context in which the individual finds the substance [14].

In the present study, although participants have 
sought help to deal with the Chemical Dependency, it is noted that throughout the life course the issue of sexual violence was not embraced and evidently treated.

The factors that contribute to the professionals identify few men with a history of childhood sexual abuse, and suggest that research in relation to this type of violence in males by clinicians is little performed; is belief by professionals that men do not tend to reveal their experiences of childhood sexual abuse, the consequences of disclosure are perceived as more harmful than the consequences of non-disclosure, because it happened in childhood and other professionals may had met this demand [15].

Thinking about the adult who was sexually abused in childhood, Dube et al. [16] pointed to the need of having them identified and treated, because the consequences of such violence do not cease upon reaching adulthood.

Studies show that sexual abuse in childhood and adolescence causes damage to physical and mental health, leading to the development of mental and behavioral disorders, sexual disorders, sexual identity conflicts, issues regarding to sexual orientation, denial and legitimization of abuse suffered in childhood or adolescence, PS abuse, among others [7]. In general, the findings also reveal a strong relationship between childhood sexual experiences with the use of PS.

Furthermore, as the reports of the participants in this study, sexual abuse suffered in childhood or adolescence although legitimized by the victims, outside silenced and seen as "something that should not have happened". The ambivalence is significantly observed in participants' speech, in which note the fear, silence, anger and desire that everything had been different.

It was observed that the subjects have a double stigma in society: the issue of addiction and orientation of sexual desire, as most of the participants are gay.

Due to this, the attitude of society towards such complex matters as the sexual abuse and the use of PS was questioned. Often society is conniving, preferring to be silenced than choosing to face in such matters. However, considering to contribute to the fully development of children and adolescents, these are issues that need to be discussed openly with them.

Regarding to preventing sexual abuse, it is necessary to talk openly about sexuality [1], and this is unlikely, since this issue is not brought to children and adolescents, and when the issue is talked, it does not include the discussion about sexual violence. As the researcher said: "thinking about possible solutions to the problem of sexual violence involves, thinking about children and adolescents as active-protect from violence and abuse does not mean isolating them from the world, but prepares them to deal with these situations" [1].

It is important to emphasize that sexual violence is a reality that haunts all of the different social classes, ethnicities and cultures, and the adolescents are exposed to PS, because access to them is easy. Do not just say no to the use of these substances, teenagers should be instilled the consequences thereof, and other possibilities to resolve their conflicts.

Sex education is necessary to prevent sexual abuse, because if the child has freedom and an affable environment to talk about sexuality, she will feel free to expose potential episodes of sexual abuse [4].

\section{Conclusions}

Sexual violence is a flagship issue in the current context. Increasingly gaining ground in society is questioned on various social levels. However, it is necessary that the discussions of theoretical nature able to be effectively applied, so that the alarming statistics of victims of abuse can be mitigated. Therefore, it is necessary to articulate effective coping strategies, whereas the DQ is a public health problem, with adverse consequences for the Brazilian population and other countries.

The results of this study highlight the need for effective actions to accommodate the victims of sexual 
violence, and effective preventive measures to prevent children and adolescents are abused. Furthermore, even unveil the need for a thorough review of early intervention when one considers the situation of abuse, it is necessary to help ensure that adolescents do not use alcohol or other SPA, or have risky sexual behavior.

A comprehensive and systematic sexual education can be a useful possibility. Inside, you can work on different subjects, such as sexual violence, and the orientation of sexual desire. Urge break stigmas, prejudices and taboos, especially because it can not be more consistent that children and adolescents are physically and emotionally abused, being pushed to make use of the SPA as a solution to their ills.

Considering that sexual abuse in childhood and adolescence is a risk factor to the use of SPA in adolescence and adulthood, it is important that professionals, especially those who watch addicts, investigate this possibility, so that these people are obviously treated and accepted. Therefore, it is necessary to examine in detail the possibility of using these substances as a way of coping or escape from the situation of sexual abuse, particularly in cases in which adult patients successive relapse.

Moreover, these professionals are instructed about the signs that students who use SPA feature so that they can make proper referrals, thinking of helping them. In fact, it is necessary that these professionals are prepared to address sexual education in the school setting, because working with sexuality is also in the preventive work of the students regarding sexual violence and drug use.

Finally, the results highlight the importance of effective preventive measures to prevent children and adolescents are abused and both health professionals, as education need to be aware of the dialogue of sexual violence with substance abuse.

\section{References}

[1] T.S. Landini, O professor diante da violência sexual, São Paulo, Cortez, 2011.

[2] A.C.B. Maia, A.F. Maia, Sexualidade e Infância, MEC/SEF, Brasília, 2005, pp. 87-97.

[3] E.R. Gauderer, Abuso sexual na infância e na adolescência, Rio de Janeiro, Rosa dos Tempos, 1993, pp. 65-80.

[4] A.M.C. Leão, Estudo analítico-descritivo do curso de Pedagogia da UNESP de Araraquara quanto à inserção das temáticas de sexualidade e orientação sexual na formação de seus alunos, Ph.D. Thesis, Faculdade de Ciências e Letras da Universidade Estadual Paulista, Araraquara, Brasil, 2009.

[5] A.C.B. Maia, Sexualidade e deficiências no contexto escolar. Ph.D. Thesis, Faculdade de Filosofia e Ciências, Universidade Estadual Paulista, Marília, Brasil, 2003.

[6] M.A. Azevedo, V.N.A. Gerra, Crianças Vitimizadas: a Síndrome do Pequeno Poder, Iglu, São Paulo, Brazil, 2007.

[7] S.G. Arreola, T.B. Neilands, R. Diaz, Childhood sexual abuse and the sociocultural context of sexual risk among adult latino gay and bisexual men, American Journal of Public Health 99 (2) (2009) 432-438.

[8] S.R. Dube, R.F. Anda, C.L. Whitfielod, D.W. Brown, V.J. Felitti, M. Dong, et al., Long-term consequences of childhood sexual abuse by gender of victim, American Journal of Preventive Medicine 28 (5) (2005) 430-438.

[9] T.J. Schraufnagel, C. Davis, W.H. George, J. Norrisc, Childhood sexual abuse in males and subsequent risky sexual behavior: A potential alcohol use pathway, Child Abuse \& Neglect 34 (5) (2010) 369-378.

[10] E. Boruchovitch, O uso e abuso de drogas na adolescência, 2nd ed. Petrópolis, vozes, 2000, pp. 192-204.

[11] M.A.S. Paulito, A pesquisa qualitativa e a história de vida, Disponível em: http://www.uel.br/revistas/ssrevista/c_v2n1_pesquisa.htm (accessed in Sept. 25, 2012).

[12] L. Bardin, Análise de conteúdo, Lisboa, Edições, 1977, p. 70.

[13] E.A. Silva, D. Micheli, Adolescência, uso e abuso de drogas: uma visão integrativa, São Paulo, Unifesp, 2011.

[14] M. Ribeiro, R. Laranjeira, O tratamento do usuário de crack, Porto Alegre: Artmed, 2012.

[15] W.C. Holmes, G.B. Slap, Sexual abuse of boys: definition, prevalence, correlates, sequele, and management, JAMA 280 (21) (1998) 1855-1162.

[16] S.R. Dube, R.F. Anda, C.L. Whitfielod, D.W. Brown, V.J. Felitti, M. DONG, et al., Long-term consequences of childhood sexual abuse by gender of victim, American Journal of Preventive Medicine 28 (5) (2005) 430-438. 